\title{
Uma breve reflexão acerca do Lume e seu Japão imaginado*
}

\author{
Christine Greiner
}

1

um fim de tarde chuvoso, em meados nos anos 80, conheci Luís Otávio Burnier. Eu havia estudado dança desde criança, passado pelo jornalismo, estava matriculada no curso de Direito da São Francisco e começava uma pesquisa na área de comunicação e semiótica na PUC, girando em torno de uma série de idéias sem saber exatamente para onde ir.

Neste contexto caótico, a figura descabelada de Burnier logo me fascinou. Os olhos muitos espertos, sem fixar exatamente em ponto algum, mas abanando os braços e cruzando na mesma conversa, kabuki, bumba-meu-boi e Étienne Decroux. Anos depois, nos reencontramos algumas vezes em eventos, apresentações e, não por mera coincidência, acabamos partilhando o mesmo orientador de doutorado, o professor Norval Baitello Jr.
A fascinação pelo Japão sempre fez parte de nossas conversas. Num primeiro momento, lembro do interesse de Burnier pelos teatros tradicionais, especialmente o nô e o kabuki, e só depois pelo butô. Nessas "viagens" pela cultura japonesa, a participação da atriz e professora da Unicamp, Alice K., foi bastante importante. Ela também havia voltado de um período de estudos no Japão e partilhava conosco a experiência nô.

Mas entre todas as passagens, a ocasião mais marcante (e madura) referente às aproximações do Lume com o Japão, não teve nada a ver com as conversas de botequim, mas aconteceu durante a ida da coreógrafa Anzu Furukawa a Campinas. Anzu montou um trabalho belíssimo com o Lume, inspirado em Cem Anos de Solidão, de Gabriel Garcia Marquez - infeliz-

Christine Greiner é professora do Programa de Estudos Pós-Graduados em Comunicação e Semiótica da Pontifícia Universidade Católica de São Paulo.

* Desde a década de 1980, quando o mestre Kazuo Ohno apresentou-se pela primeira vez no Brasil, muitos artistas ficaram encantados com aqueles corpos tão distintos de tudo que parecia conhecido até então. Além do butô, os teatros nô e kabuki, também apresentavam imagens e treinamentos bastante específicos e fascinantes. Através de seu fundador Luis Otávio Burnier, o Lume foi fisgado pelo que o crítico de cinema Donald Richie chama de "Japanese bug", um inseto imaginário capaz de aprisionar afetivamente suas vítimas para sempre. Este artigo busca identificar o "Japão do Lume". Em vez de focar nos vestígios das imagens e dos treinamentos, investiga parentescos entre alguns entendimentos do corpo e suas percepçōes, sobretudo através do contato com o butô, experimentado pelos atores do Lume a partir de diferentes convidados e residências. 
mente já depois da morte de Burnier. Naquele dia, fui a Campinas para escrever um artigo, em seguida publicado no Caderno 2 do jornal $O$ Estado de S. Paulo. Mas, para mim, foi muito mais do que uma reportagem. Observando o corpo dos atores, durante o ensaio, entendi que a pesquisa havia de fato "encorpado". A combinação dos estudos da dança pessoal, desenvolvida a princípio por Carlos Simioni, e da mímesis corpórea, concebida a partir de Burnier; mas, de fato, emergente de um experimento coletivo, abria possibilidades na cena e fora dela.

Nos últimos vinte anos, além de Anzu, outros convidados estiveram no Lume para trabalhar com butô. Tomando café em um saguão de teatro em Tóquio, Natsu Nakajima comentou comigo, três anos atrás, como havia sido prazeroso conhecer os atores em Campinas. Que vitalidade existia neste (aparentemente) pequeno centro de pesquisa!

Mas que Japão é este que tanto tem encantado o Lume? Onde está o butô? A hipótese deste artigo é a de que, pensando nas apresentações mais recentes e nos caminhos do pensamento butô, ele está mais presente em Café com Queijo (1999) do que em Shi-zen, 7 cuias (2000), dirigido por Tadashi Endo.

\section{Quando um corpo muda de estado}

A exemplo do Lume, o butô também nasceu absolutamente mestiço. A complexa malha poética tecida por Tatsumi Hijikata a partir do final dos anos 50, a exemplo do que testava Burnier, não tinha uma nacionalidade estrita, mas uma curiosidade atravessada por domínios diversos. Entre a tradição dos massagistas cegos do Japão rural, Antonin Artaud, Jean Genet, Picasso, Klimt, Wolz, o antigo kabuki e o jazz ritual de Katherine Dunham, Hijikata formulou uma metodologia para testar a mudança de estado dos corpos, reconhecendo que existia sempre um à beira de ..., antes de toda ortodoxia, toda religião, no fluxo dos afetos e da expe- riência aberta à fome epistemológica e à iminência da morte.

As dificuldades para trabalhar neste território muito se assemelham às investigações de uma possível "mímesis corpórea". Quando um corpo se encontra em estado de crise, sem verdades dadas, rompe a membrana imaginária que, de algum modo, separava os sistemas arte e vida. Tais fronteiras eram, na verdade, um alívio necessário para historiadores da arte, críticos e para o público em geral. Por isso a crise, que não é apenas temática, fere e perverte a materialidade do sistema no qual se encontra, exigindo uma configuração distinta para ser observada. Os limites são de uma plasticidade intolerável, sacrificando dualidades do tipo sujeito e objeto, universo real e universo simbólico, corpo e corporeidade.

Para entender a ambivalência que trafega entre o estável e a sua desestabilização, Hijikata não buscava "vocabulários" ou passos de dança. Nem parecia contrapor-se ou aliar-se a esta ou aquela estética já estabelecida. A despeito de todas as interpretações que se tornaram habituais nas histórias da dança e da arte no Japão, ele não queria negar o passado, apagar a história, nem tampouco "propor novidades". As suas questóes eram de outra natureza e diziam respeito, antes de tudo, à investigação de campos de percepção ainda não suficientemente pesquisados.

Mas é preciso tomar cuidado. A abertura do butô às culturas estrangeiras, que é um fenômeno bastante marcante no Japão, após a Segunda Grande Guerra, não significava a ausência de especificidade na busca de um caminho próprio. Também não era uma sugestão para construir um corpo apolítico, ahistórico. Como dizia o poeta Shûzô Takiguchi, é bom olhar para a experiência dos "outros", mas em certos momentos sentimos um enfastiamento que pede pela digestão solitária, pelo fluxo do tempo e o entendimento da identidade própria, ainda que mestiça.

A trajetória de Café com Queijo lembra esta experiência. $\mathrm{O}$ envolvimento com as con- 
versas, as histórias, as canções, os versos ditos em voz alta e também aqueles silenciosos desenhados no corpo. Uma experiência do tempo que ora corre solto, ora se suspende, mas guarda sempre a aptidão para criar. Lá estão resíduos de Barba, Decroux, clowns, sussurros de Yoshi Oida e assim por diante. Mas há também uma brasilidade que não nasce dos símbolos do Brasil, nas imagens estereotipadas, mas em ambientes específicos, nos quais a natureza da coisa torna-se a natureza das situaçôes. Há um derramamento do sujeito nas açōes, nos ambientes e vice-versa. São os ambientes visitados e imaginados que atravessam o corpo e o desestabilizam.

Assim deveria ser também a imagem do Japão evitando, no caso específico do butô, toda e qualquer semelhança com o modelo estético depreendido das experiências e congelado em cartão-postal. O problema em Shi-zen é evidente. Tadashi Endo entende o butô em uma das suas conexões possíveis no mundo contemporâneo. Essas habitam um fluxo de imagens que partem do Japão, são reapresentadas fora de lá e voltam a ser imitadas pelos próprios coreógrafos japoneses. De alguma forma, esta experiência tornou-se inevitável como estratégia de sobrevivência no mercado internacional, mas há outras maneiras de se aproximar dos procedimentos tão profundamente investigados pelos artistas do butô, sobretudo os das duas primeiras gerações, indagando inúmeros aspectos aparentados com as questôes mais fundamentais do Lume: a relação entre o dentro e o fora do corpo, as tensões entre a representação e a sua impossibilidade, o traço autobiográfico como engendrador dos processos, a transição entre o informe e a forma organizada com sentido a partir da experiência e jamais dada a priori.

A contribuição do butô para o Lume será tanto mais fértil ao alimentar este tipo de laboratório processual e não a imagem que acabou se estabilizando, sobretudo após a sua divulgação pelo mundo ocidental. Como tem ocorrido com outras experiências artísticas em culturas diversas, aquilo que no decorrer do processo evolutivo é transformado em produto, testemunha o desaparecimento do processo e junto com ele a história, os manifestos, as questôes. Não se trata de estabelecer um juízo de valor para dizer se a pesquisa de Endo é boa ou ruim ou se a convivência com o grupo foi ou não interessante. Gostaria apenas de lembrar a sugestão do pesquisador Nario Goda, após a morte de Hijikata. Goda lembrou a todos que era importante voltar para casa. Investigar o butô nos ambientes em que vivemos. Esta seria a única forma de mantê-lo vivo. A dificuldade desta tarefa é que não se trata de fazer qualquer coisa em qualquer lugar. Butô não é terapia, autoconhecimento aleatório, nem toda e qualquer improvisação.

Sobretudo entre as décadas de 1960 e 1970, o pensamento butô explorou as ambivalências do que significa estar no mundo a partir de questôes nascidas do trânsito com alguns pensadores estrangeiros devorados à luz do budismo, não na sua referência especificamente religiosa, mas em alguns modos de entendimento do que seria dissolver o si mesmo. O objetivo era, paradoxalmente, garantir uma singularidade das açôes, abrir-se para o outro e mergulhar nas profundezas do próprio corpo, construindo mediações ainda não experimentadas com o ambiente, desautomatizando o organismo e, ao mesmo tempo, permanecendo vivo. Estas foram questôes que, por sua vez, transformaram-se no exercício de perverter a motricidade comum para recriar os movimentos. Subverter o tempo, nascendo da entropia. É neste sentido que a revolução perde sua nacionalidade e ocorre no Japão, no Brasil e em todos os lugares onde o corpo deixa de ser "o corpo" para se tornar processo. Hijikata reconhecia estes exercícios, por exemplo, no balé de Vaslav Nijinsky. Um corpo no qual olhos menos treinados jamais veriam butô.

A partir dessa discussão, não raramente organizada nas bordas entre a lucidez e a insanidade, que seria também a ponte entre o corpo vivo e o corpo morto, ilumina-se o enfrentamento da finitude e das descontinuidades. Esta sim a grande questão. Muitas passagens e entre- 
lugares passam a ser trilhados, e o pensamento, neste viés, torna-se irreversivelmente o pensamento do corpo.

Segundo o grande diretor de teatro japonês Tadashi Suzuki, esta constatação já era uma chave importante para o nô, que fora do Japão era visto como um modelo pronto, dado, codificado e meramente aplicável, a exemplo do que ingenuamente se dizia do balé ocidental e da mímica. No entanto, o ponto de partida sempre foi a capacidade de apresentar uma forma específica da arte no corpo artista, de modo inseparável do ambiente onde ele a havia construído. Assim, cada vez que um padrão era implementado, pedia uma nova organização do corpo naquela circunstância específica, mostrando que, de fato, não existe repetição. Isso vale também para os pensamentos. Ao serem transmitidas, as idéias são inevitavelmente reconstruídas. Por isso ninguém pode ensinar nada para o outro. O que fazemos é emprestar igniçōes.

O colapso dos entendimentos do corpo a partir dos treinamentos nascidos das experiências de meados do século XX, trouxe à luz discussões que indagavam o que é e como se experimenta o estado de ser vivo. O que colapsa do corpo, neste viés, são as fórmulas prontas como um engessamento do saber descolado do fazer.
Esta me parece a chave das experiências do Lume e a própria noção de mímesis corpórea que nunca foi a imitação de algo pronto, mas a construção de um estado. Como estamos no Brasil e em um momento político complexo como aqueles em que nasceram o Lume e o butô, é preciso pensar acerca de algumas escolhas.

Hijikata era um tirano. Jamais partilhou com seus dançarinos a riqueza de sua pesquisa. Assim, os dançarinos seguiram seus próprios caminhos, conhecendo em parte as questões e transmitindo-as também aos pedaços para a genealogia de artistas que colocou o pensamento butô e sua metodologia inacabada em evolução.

Nós, no Brasil, trabalhamos de outra forma, seja nos centros de pesquisa das universidades como é o caso do Lume ou fora deles, através do florescimento cada vez mais evidente de coletivos inteligentes. O doutorado de Renato Ferracini "Café com Queijo, corpos em criação" é uma amostra da potência investigativa de nossos artistas-pesquisadores. Eu diria então que, uma vez estando com a faca e o queijo na mão, com o perdão do trocadilho sem graça, é hora de caminhar com os próprios pés, descansando dos mestres no caminho que já vem sendo trilhado pela autonomia dos atores. 